\title{
Preclaridades da noção de representação
}

\author{
Marianne Lacomblez ${ }^{\text {Orcid, } \star}$ \\ Universidade do Porto, Porto, Portugal
}

Resumo

Pretende-se neste artigo contribuir para o esclarecimento da noção de "representação" no campo da Psicologia do trabalho e da Ergonomia da atividade, situando-a no quadro de duas abordagens. A primeira abordagem, que é tributária da noção de "imagem operativa", está associada à categoria de análise das "representações para a ação" e à proposta metodológica de "trabalho de representação". A segunda é relativa ao estudo das representações ditas "sociais" que resultam de processos de interação social no campo da construção de opiniões, crenças e atitudes. Os dois paradigmas assim envolvidos evidenciam potencialidades e limites em relação à compreensão das "questões vivas" das atividades de trabalho. Estudos empíricos sustentam a argumentação deste artigo que propõe uma abordagem alternativa, baseada, nomeadamente, nos contributos de Yves Schwartz e, igualmente, de Alessandra Re. Privilegia-se então a distinção entre várias formas de saber - saberes instituídos e saberes investidos - que, no debate e na controvérsia, tendem, na análise do real das atividades de trabalho, a construir uma linguagem comum.

Palavras-chave: psicologia do trabalho; ergonomia da atividade; noção de representação; atividade de trabalho.

\section{Distinctions of the notion of representation}

\begin{abstract}
In this article we intend to contribute to the clarification of the notion of "representation" in the fields of Psychology of Work and Activity-Centered Ergonomics, distinguishing the concept within two approaches. The first one, based on the notion of "operative image", is associated to the analytical category of "representations for action" and to the methodological proposal of "work of representations". The second one refers to the study of the so-called "social" representations that result from processes of social interaction within the framework of the construction of opinions, beliefs and attitudes. The two paradigms involved in these two approaches show potentialities and limits when "applied" to the work activities. Empirical studies support the argumentation of this article who ends with an alternative proposal - based, in particular, on the contributions of Yves Schwartz and also of Alessandra Re. Instead, it favors the distinction between various forms of knowledge - instituted knowledge and invested knowledge - that, in the debate and in the controversy, tend, in the analysis of the real of the work activities, to construct a common language.
\end{abstract}

Keywords: psychology of work; activity-centered ergonomics; notion of representation; work activities.

\section{1- Introdução}

A tradição científica, em que inscrevemos as nossas investigações e intervenções na Universidade do Porto, associa estreitamente a Psicologia do trabalho à Ergonomia da atividade. Faz, então, parte dos nossos fundamentos teóricos e metodológicos a noção de "imagem operativa", tal como foi perspetivada por Dimitri Ochanine e posteriormente assimilada, por diversos autores, à categoria de análise das "representações para a ação".

A literatura enraizada nesses contributos é vastíssima, tendo colocado o termo "representação" no glossário de uso quotidiano de inúmeros investigadores, passando assim, e durante muitos anos, a constituir um dos principais reveladores do paradigma de uma ampla escola científica. Porém, certa ambiguidade do estatuto epistemológico desta noção provocou um progressivo decréscimo da sua utilização.

Distintamente, as evoluções de algumas correntes da Psicologia social acabaram por manter constante o estudo das representações, ditas "sociais", despertando recentemente, no âmbito de colaborações multidisciplinares, o interesse e a atenção de alguns ergonomistas. Deste modo se desencadeou uma controvérsia, em relação à qual gostaríamos aqui de contribuir para o seu esclarecimento.

^Endereço para correspondência: Centro de Psicologia da Universidade do Porto (CPUP). Faculdade de Psicologia e de Ciências da Educação da Universidade do Porto. Rua Alfredo Allen, 4200-135 Porto, Portugal.E-mail: lacomb@fpce.up.pt

\section{Da 'imagem operativa' às "representações para a acção": transformar um "não lugar" em "lugar"}

\subsection{O contributo de Dimitri Ochanine e seu contexto}

Tal como Annie Weill-Fassina relembrou (2013), Dimitri Ochanine (1907-1978) nasceu na Rússia, vivendo depois em vários países europeus, em razão dos acasos da emigração. Defendeu a sua tese de doutoramento em 1938 em Paris, regressando à URSS em 1955, após a morte de Estaline, tendo lhe sido atribuído o título de Diretor de Investigação do Instituto de Psicologia da Academia de Ciências Pedagógicas, de Moscovo, onde exerceu a função de Diretor do Laboratório de Psicologia do Trabalho do mesmo Instituto. Reestabeleceu-se em Paris em 1975, tendo aí lecionado em várias universidades.

Podemos sintetizar o núcleo da sua abordagem citando um extrato de um dos seus artigos mais importantes, que evidencia o que o levou a distinguir a "imagem cognitiva", coerente com os conhecimentos existentes e considerada como sendo exaustiva e rigorosa, da "imagem operativa", relacionada, esta, com a ação, funcional, parcial e incompleta, não sendo, no entanto, entendida como incorreta nem, simultaneamente, objeto de julgamento negativo. Ochanine (2013, p. 95) afirma, portanto:

A ação sobre um objeto pode ser definida como um processo em que a informação sobre os estados sucessivos do objeto é transformada em ações finalizadas sobre esse objeto. Esta transformação opera-se na sequência de uma confrontação da informação proveniente do objeto com aquela 
que o sujeito já dispõe, por exemplo, a informação sobre a forma ou a estrutura do objeto, o estado requerido, o algoritmo do seu funcionamento enquanto sistema dinâmico, etc. Esta informação pré-existente com a qual é confrontada a informação exterocetiva aparece muito frequentemente organizada numa imagem operativa [...] caracterizada antes de tudo pela sua ordenação estrutural [...] permitindo a apreensão do conteúdo informacional dos sinais.

Lembrar o contexto em que foram desenvolvidas e realizadas as pesquisas empíricas que fundamentaram tal abordagem esclarece sem dúvida o seu significado. A época dos anos 60 do século passado corresponde de fato, no seio das empresas dos países industrializados, à implementação progressiva do que estavam a permitir evoluções tecnológicas, interpondo novos dispositivos (sinais, indicadores, intermediários gráficos...) na relação do operador com o processo de produção. Tais dispositivos retratam, assim, a progressão do decurso produtivo, orientando e condicionando as intervenções do trabalhador, mas exigindo igualmente da sua parte, em geral sob fortes condicionalismos temporais, codificação e descodificação das informações disponíveis, interpretações, raciocínios ativos, etc. Tais situações, e respetiva dinâmica e complexidade, também despertaram obviamente o interesse de outros pesquisadores, e em particular na América do Norte, onde alguns chegaram a formular hipóteses semelhantes às de Ochanine (ver por exemplo: MILLER; GALANTER; PRIBAM, 1960). ${ }^{1}$

Uma outra questão, que passa também a ser central, está relacionada com o modo de conceber tais situações. Isto porque, frequentemente, são definidas a partir daquilo que os conceptores iniciais pensaram ser o mais adequado e racional no âmbito da organização geral do processo de produção, e tendo em conta a função planejada para o operador. Tais dispositivos são configurados, por isso, não raras vezes, em moldes que, na realidade, exigem o desenvolvimento de modos operatórios distintos dos previstos. Daí que o operador os vá redefinindo aos poucos, através de tentativas e de erros, afinando progressivamente estratégias, a fim de, apesar da urgência e dos riscos eventuais, conseguir levar a cabo o que dele é esperado e/ou exigido.

É este trabalho de "remodelização" que Ochanine sintetizou na "imagem operativa", e que pode ser considerada como prelúdio da noção de "regulação" em Psicologia do trabalho e em Ergonomia da atividade (FAVERGE, 1966), e igualmente das "representações para a ação" definidas mais tarde (WEILL-FASSINA, RABARDEL; DUBOIS, 1993). ${ }^{2}$

Este regresso a alguns dos fundamentos destas nossas disciplinas obriga-nos a relembrar ainda as exigências metodológicas que advieram deste olhar pousado sobre o trabalho humano: uma observação da atividade do(s) operador(es) - guiada pelo principio de que é preciso tempo

\footnotetext{
G. A. Miller e seus colegas sublinham o caráter essencialmente dialético da relação indivíduo/realidade: o ser humano vai construindo representações sobre a "realidade", que baseiam os seus "planos de comportamento" - planos esses que irão transformar alguns aspetos da "realidade" e, em eco, as representações que dela se constroem.

2Obviamente, subjazem, nesta abordagem, a categoria de análise, básica nesta tradição científica, que distingue o trabalho "prescrito" do trabalho "real", e uma outra, a ela associada, que diferencia a tarefa e a atividade (ver, e.a. SCHWARTZ, 2005; OUVRIER-BONNAZ; WEILL-FASSINA, 2015).
}

para entender procedimentos, eles próprios, construídos no tempo expandido da aquisição da experiência; observação articulada sobre momentos de explicitação das estratégias de regulação elaboradas e também atenta à diversidade dos modos de resolução de dilemas face a constrangimentos dificilmente conciliáveis, nomeadamente quando se entrecruzam as lógicas da produção com as da preservação da segurança e da saúde dos operadores.

Em consequência, exige do investigador, não só a persistência de quem sabe que a atividade, sua evolução e sua especificidade é, como escreveu Jean Marie Faverge, um alfinete que se procura num palheiro (FAVERGE, 1966), mas igualmente a convicção de que a relação estabelecida entre o analista e o operador é, intrinsecamente, a de uma confrontação de saberes sem hierarquização das atividades cognitivas (LACOMBLEZ, 2007).

\subsection{O "trabalho de representação" na dinâmica da compreensão e transformação do trabalho}

Podemos agora perceber como, a partir dos anos 70, este paradigma acabou por gerar, em resposta às solicitações de delegados sindicais preocupados com a deterioração acentuada da saúde de algumas categorias de trabalhadores, uma proposta que Catherine Teiger (1993) designou por "trabalho de representação". Trata-se, com efeito, de cenários de intervenção em que o ergonomista, no seu diálogo com os trabalhadores, acompanha e documenta ativamente o processo de explicitação das "representações para a ação", e suas evoluções, no âmbito de um questionamento de tipo maiêutico. Tal questionamento se traduz na progressiva sistematização da análise das situações de trabalho, na procura de um uso adequado e enriquecedor, mas também crítico, de categorias de análise e de conceitos que serão os pilares de uma "formação-ação", cuja finalidade será a de realçar e compreender melhor o que é exigido a cada um no uso de si, avançando a partir daí na definição de estratégias que irão permitir a implementação de melhorias nas situações de trabalho.

Neste trabalho de tipo reflexivo, os conhecimentos são associados a critérios de veracidade e de objetividade: "podem ser confirmados ou não, completados ou corrigidos, ou então enriquecidos de dados novos" (TEIGER, 1993, p. 323, tradução nossa). Distinguem-se por isso das representações em que predominam critérios de coerência e de eficácia na ação - representações essas que não podem ser contestadas, mas sim modificadas por meio da aquisição de conhecimentos novos, sendo enriquecidas graças à descoberta de relações entre os elementos que a constituem e transformadas pela modificação dos objetivos, da função assegurada, da representação de si e da relação com o trabalho (TEIGER, 1993). Reencontramos deste modo a distinção inicial de Ochanine entre imagem cognitiva e imagem operativa - abrindo, contudo, e deliberadamente, a hipótese do questionamento e da destabilização dos conhecimentos, da possível descoberta de lacunas essenciais nos saberes disponíveis. Relembraremos também que a cooperação entre ergonomistas e militantes sindicais foi determinante no entendimento do contributo do registro dito das representações, quan- 
do desvelou a fragilidade dos conhecimentos existentes no que dizia respeito, por exemplo, aos componentes fisiológicos do "sono de dia dos trabalhadores de noite", ao "caráter pesado de trabalhos ditos leves" em tarefas repetitivas, ou ainda relativamente ao envelhecimento precoce de jovens operárias (TEIGER et al., 2014). E, de fato, pesquisas complementares foram desenvolvidas posteriormente, constituindo hoje saberes sólidos, nomeadamente em matéria do trabalho por turnos (BARTHE, 2015; QUÉINNEC; TEIGER; TERSSAC, 1985) ou nas questões do envelhecimento no e pelo trabalho (MARQUIÉ; PAUMĖS; VOLKOFF, 1995; MOLINIÉ; GAUDART; PUEYO, 2012).

\subsection{A construção de uma linguagem comum}

Abrir a porta a uma desestabilização dos conhecimentos e reconhecer a fragilidade da "fronteira" entre representações e conhecimentos, distinguirão, então, os investigadores que aceitam ou procuram uma ruptura paradigmática.

Ivar Oddone inscreveu-se nesta postura quando, ainda médico generalista, no decorrer dos anos 60, na Itália, no âmbito do seu diálogo com trabalhadores, cujo estado de saúde era profundamente determinado pelas condições em que exerciam a sua atividade profissional, teve consciência da necessidade de uma mudança completa das categorias de análise que, até aí, tinham apoiado os seus diagnósticos (ODDONE, 2013). Os saberes académicos, na base dos quais ele se fundamentava, ignoravam por completo aquilo que caraterizava realmente o dia a dia do trabalho industrial. Foi este o ponto de partida de um percurso, que passou a ser coletivo (ODDONE; RE; BRIANTE, 1977), e que encontrou parte da sua sustentação teórica em autores como Miller e seus colegas, já aqui referenciados por defenderem modelos de análise muito próximos dos de Ochanine (MILLER; GALANTER; PRIBAM, 1960).

Atualmente, o contributo da equipe de Torino é bem conhecido (MUNIZ et al., 2013; VASCONCELOS; LACOMBLEZ, 2005), nomeadamente através da afirmação de uma "comunidade científica ampliada", procurando uma linguagem que torne permeável a interface entre os pesquisadores e os trabalhadores. Foi esta a via definida, e não a do encontro entre representações e conhecimentos, para promover cenários de intervenção no quadro da problemática da nocividade do trabalho. Transformando assim um "não lugar" em "lugar", graças à construção de uma linguagem "comum", que "não é nenhuma das linguagens de partida, mas será uma linguagem construída pelos atores, sendo, deste modo, uma linguagem de chegada" (RE, 2013, p. 646, tradução nossa).

Sublinharemos que, a partir do percurso de Oddone e seus colegas, como também de outras trajetórias semelhantes, Yves Schwartz (2000) passou a referir o "desconforto intelectual" intrínseco a esta postura e à abordagem a ela associada. De notar ainda que, tal como a equipe italiana, Schwartz não privilegiou a noção de "representação". Com efeito, a Ergologia não a insere no seu glossário (DURRIVE; SCHWARTZ, 2008), não sendo por isso associada à noção de conhecimentos. Aqui, a distinção, a confrontação e o diálogo, convocam, por um lado, os "saberes instituídos", de cariz académico, "legitimamente descontextualizáveis, saberes constituídos em uma relativa desconexão do aqui e agora"; e, por outro lado, os "saberes investidos", enraizados na experiência da atividade de trabalho, "memorizados ou produzidos no tratamento diário das tarefas, na gestão das interfaces sempre infiéis, configurando as situações locais de trabalho" (SCHWARTZ, 2013, p.19; 29; 30).

Existiram, na verdade, evoluções da reflexão nesta matéria que se traduziram, nomeadamente, no campo da Psicologia do trabalho e da Ergonomia da atividade, num recurso menos acentuado da noção de representação (para a ação), embora tal tendência não seja acompanhada de uma renúncia da abordagem que se afirmou a partir dos anos 70 .

Tal noção estará ultrapassada, obsoleta? Será que o desalento que pode suscitar a categoria de análise "representação $><$ conhecimento", associando às representações um estatuto epistemologicamente precário, incitará os investigadores a colocá-la na margem das suas análises e assim privilegiar a questão do debate entre diferentes registros de saberes?

\section{O "momento" (WORMS, 2009) dos anos 60}

\subsection{A potencialidade heurística do ato concreto}

$\mathrm{Na}$ verdade, no contexto histórico em que emergiram as abordagens referidas, foram também formulados outros projetos de intervenção, não restritos ao mundo do trabalho, firmemente ancorados no "concreto", no "local" e sustentados pela convicção de que existem vários tipos de conhecimento e diversos modos de os explicitar, através do recurso a uma grande variedade de linguagens.

Aliás, Frederic Worms (2009) não hesitou em referir o "momento dos anos 60" como caracterizado pelas evoluções que tiveram lugar em diversos campos do saber e da ação. Evoluções essas que consagram a valorização da diversidade, a recusa das categorias de análise que legitimam as hierarquias sociais e o questionamento de uma "monocultura do conhecimento" assente no postulado da verdade única da ciência moderna, configurada através de normas predefinidas aplicáveis à sua produção (científica).

Os autores já referidos ajudam-nos a perceber a importância atribuída ao significado latente do ato concreto: um ato que pode, à primeira vista, parecer banal, mas cuja riqueza é potencialmente heurística, abrindo novas ambições para a análise, suscetíveis de transformar o 'drama' individual numa matéria essencial da história coletiva.

Tal perspectiva ocupa igualmente um lugar central no legado de Paulo Freire (1994), como também na obra de muitos filósofos da época, nomeadamente na de Jean Paul Sartre, referência privilegiada por Catherine Teiger.

Nestas abordagens, obviamente, o foco no "local" nunca esquece a sua inclusão no "global", porque são indissociáveis. Não se trata de uma questão de articulação oportuna de escalas de análise, mas sim de um desafio suscitado por um método presidido pela preocupação do respeito constante dessa integração. 


\subsection{Perceber o "senso comum"}

É também nesta conjuntura, e movido por preocupações semelhantes, embora caminhando para horizontes distintos, que Serge Moscovici (1961) vai optar por reorientar a proposta apresentada por Émile Durkheim (1894/2009) no sentido de consagrar a Psicologia social ao estudo daquilo que este último designou "as representações coletivas". Esta proposta de Durkheim tinha como objetivo permitir apreender com maior precisão a estrutura social da "nova sociedade industrial", fundada na "solidariedade orgânica", 3 devendo tal enfoque contribuir para a melhoria do equilíbrio e da dinâmica sociais. Nesta perspectiva, as representações coletivas são entendidas como determinando a maneira como os indivíduos pensam, sentem e se representam o mundo, e igualmente como entre eles comunicam. Tais representações configuram, assim, de forma inconsciente, as representações individuais (POESCHL, 2013).

Moscovici decide realçar o caráter dinâmico, evolutivo de tais representações, considerando-as como não sendo coletivas, nem individuais. Passa, por isso, a designá-las de "sociais", de modo a evidenciar que resultam de um processo de interação social: cada pessoa ao interagir com outras, acaba por compreender o meio em que está inserida, no âmbito de um processo de construção de opiniões, crenças e atitudes.

Moscovici insiste ainda sobre o fato da emergência das representações sociais não resultar de um tratamento rigoroso de informações. Aliás, Denise Jodelet (1997, p. 36) defende que a teoria das representações sociais é uma teoria do senso comum, do conhecimento ingênuo, por isso, claramente distinto do conhecimento científico: a representação social

[...] é uma forma de conhecimento socialmente elaborado e partilhado, que detém uma finalidade prática e concorre à construção de uma realidade comum para um conjunto social.

Ela não é o simples reflexo da realidade, mas funciona como um sistema de interpretação da realidade que organiza as relações entre os indivíduos e seu meio e orienta as suas práticas.

A representação social constituirá, assim, o objeto de pesquisa específico da Psicologia social, tal como Moscovici a definiu ${ }^{4} \mathrm{e}$, posteriormente, retrabalhada, enriquecida e, por vezes, reorientada por várias "escolas". Entre essas escolas, destacaremos duas que são "historicamente reconhecidas: a de Aix en Provence e a de Genebra que se diferenciam, como 'estruturalista'e 'sociogenética', da perspectiva mais clássica correspondente às orientações delineadas por Moscovici" (JODELET, 2011, p. 21). Não pretendemos aqui desenvolver o que sustenta e explica tais orientações. No entanto, relembraremos, a título ilustrativo, a teoria do "núcleo central" da escola de Aix en Provence que se baseia na hipótese de que uma represen-

\footnotetext{
${ }^{3} \mathrm{Na}$ análise de Durkheim, trata-se da forma mais desenvolvida de sociedade, no seio da qual, tal como num sistema de órgãos de um ser vivo, cada indivíduo tem de cumprir uma determinada função.

4 "A psicologia social andava à deriva $[\ldots]$ cada pesquisa foi uma espécie de revelação [...] o que nos chamou a atenção foi o fato de se querer ignorar o social, quando ele era a razão visível do que tínhamos criado na Europa após a guerra e foi isso mesmo que conferiu todo o interesse aos estudos de campo que eu realizei [...]" (MOSCOVICI, 2011, prefácio).
}

tação social está sempre organizada à volta de elementos cognitivos fortemente correlacionados (POESCHL, 2013). E frisaremos também a comunicação "controversial" da escola de Genebra, em que predominam "formas de argumentação que seriam consideradas inaceitáveis num debate científico: utilizar informações fragmentárias, tirar conclusões gerais a partir de observações particulares, fazer prevalecer o veredicto sobre o julgamento, basear argumentos de causalidade em associações de natureza avaliativa" (POESCHL; RIBEIRO, 2017, p. 7).

Não deixa de ser interessante referir ainda aqui a "escola brasileira", que Jodelet considera como reunindo cientistas cuja preocupação "não é tanto de tipo puramente teórico, não responde tampouco a um desejo exclusivo de aperfeiçoamento e aprofundamento de metodologias. A perspectiva comum é de usar a teoria e os modelos das representações sociais para enfrentar questões vivas que atravessam a sociedade brasileira hoje em dia", sendo por isso chamada "a desempenhar um importante papel no progresso do pensamento científico relativo às representações sociais" (JODELET, 2011, p. 22; 25).

Ora, no seu balanço das pesquisas realizadas acerca das "questões vivas", Denise Jodelet (2011, p. 22) refere que estas foram desenvolvidas essencialmente nos domínios da "educação, saúde, ambiente, política e justiça social, movimentos sociais, memória e história". Moscovici não hesitou em exprimir logo a sua vontade de discutir ainda mais sobre as áreas de aplicação, assinalando a importância da área do trabalho. Com efeito, acabou por relembrar os anos da sua "descoberta do mundo do trabalho na França, das minas de carvão, das oficinas onde as luzes estavam sempre acesas, das regiões onde se exercia a mesma profissão durante meio século [...]", confessando que só "mais tarde, eu percebi que, em relação a estes campos de interesse, foram as primeiras representações sociais que eu estava estudando sem o saber" (MOSCOVICI, 2011, "Prefácio", p. X).

Estas considerações sobre a importância da área do trabalho acabaram por ter uma certa divulgação e impacto, não unicamente nos meios da Psicologia social.

\section{A tradição do estudo das representações sociais aplicada à área do trabalho}

A tradição que acabamos de sintetizar levanta, contudo, algumas interrogações quando "aplicada" às "questões vivas" das atividades de trabalho. Como vimos, de modo geral, a finalidade dos estudos é a de uma progressão da teoria das representações sociais e das metodologias suscetíveis de sustentar novas hipóteses. E, como também o sublinhamos, este paradigma é estruturado pelo postulado da dissemelhança fundamental entre conhecimento científico e conhecimento ingênuo, criando, pois, uma relação potencialmente desigual entre o cientista e o leigo, objeto das pesquisas. No campo do mundo do trabalho, uma tal perspectiva significa que o tal leigo não será considerado como fonte eventual do questionamento dos conhecimentos, inclusive os convocados pela organização e pelas condições do seu trabalho. Em estudos ditos "aplicados", com objetivos de intervenção, ficamos 
sem saber o que o cientista, especializado em estudo das representações sociais, irá privilegiar no plano das ações de transformação, se a sua convicção da ingenuidade dos sujeitos das suas pesquisas não for inscrita num debate com todos os protagonistas efetivamente envolvidos.

Algumas pesquisas, ao articularem o tema dos riscos profissionais com certos aspetos da teoria das representações sociais (CAMPOS, 2012; CHAMON; MORAES, 2011; MOURA et al., 2013) tornaram a complexidade da problemática mais visível. E alguns ergonomistas, conhecidos por terem consagrado os seus estudos à questão da utilização dos equipamentos de proteção individual (EPI), acabaram também por orientar a sua curiosidade nesse sentido.

Dada a relevância dos dilemas e controvérsias que tais pesquisas são suscetíveis de desencadear, iremos procurar sintetizar aqui as etapas da reflexão e dos estudos daí resultantes.

\subsection{Usar os equipamentos de proteção individual: uma atividade em si}

Usar um EPI não significa necessariamente ficar protegido face ao risco que originou tal equipamento. Aliás, o recurso aos EPI tem que ser encarado como o último meio para proteger quem trabalha face aos riscos (ainda) não controlados, - sendo sempre preferível a intervenção na fonte efetiva do risco, de modo a conseguir-se a eliminação dos seus efeitos, ou pelo menos a sua atenuação.

A escassez de estudos relativos às características dos EPI e à sua utilização, não é estranha à sua conotação negativa, nomeadamente por estas duas razões: o hábito, em muitas empresas, de generalizar o seu uso sem avaliação prévia de uma intervenção na fonte; e a reprovação e condenação moral de que são frequentemente objeto os trabalhadores que não os utilizam. Felizmente que Alain Garrigou e os seus colegas têm conseguido alertar para a importância desta problemática, através da escuta das dificuldades encontradas pelos trabalhadores na utilização de certos EPI, acabando por realçar que se trata, na realidade, de uma atividade em si. Tal demonstração é baseada, entre outros, em análises relativas ao risco fitossanitário que revelam dimensões extremamente preocupantes. Além de lembrarem o facto do EPI poder dificultar o desempenho da atividade profissional em si, chamam efetivamente a atenção para os casos em que equipamentos inadequados aumentam a exposição aos riscos, agravando o estado de saúde de quem os utiliza (GARRIGOU; BALDI; DUBUC, 2008).

\subsection{Os vieses nas representações dos riscos}

Porém, escutar os trabalhadores, quando falam de proteção face aos riscos, pode conduzir o investigador a querer perceber e discutir os fundamentos das afirmações e convicções que lhe são relatadas. Daí que certos autores tenham recorrido a alguns contributos da tradição da Psicologia social, acima referida, analisando as representações sociais como construções moldadas pelas experiências (CAMPOS, 2012). Em França, Dongo Rémi Kouabénan tem-se destacado pelo seu trabalho em desconstruir "a explicação causal ingénua" avançada pelas pessoas não especializadas face ao acidente ou à ação de prevenção (KOUABÉNAN, 2007, p. 298). Tal comportamento perante o risco é então ponderado tendo em conta a percepção da utilidade das medidas de prevenção prescritas, a representação da ameaça e a aceitabilidade do custo subjetivo inerente ao cumprimento das respectivas recomendações.

Na realidade, Kouabénan desenvolve a postura que já tinha explicitado conjuntamente com Bernard Cadet: "As subjetivações da noção de risco - da sua percepção e avaliação [...] impõem-se aqui como exigências metodológicas primordiais, que se não forem satisfeitas invalidam logo o objeto de estudo, desnaturando-o", e de fato são primordiais em razão dos vieses que subjazem às percepções, declarações, atitudes, avaliações, assumidas face aos riscos e às medidas de prevenção, que acabam por interferir tanto no momento da concepção das medidas e dos equipamentos de prevenção/proteção, como nas fases da sua implementação e concretização. Trata-se pois de processos que, em virtude das interações entre "os membros de um mesmo grupo, ou comunidade, acabam por produzir uma cultura comum do risco [...] que assenta num certo número de normas e de crenças partilhadas [...] algumas delas tendendo a banalizar e a subavaliar o risco, e outras a exagerá-lo" (CADET; KOUABÉNAN, 2005, p. 18-20, tradução nossa).

Não tencionamos aqui ir mais além duma síntese desta abordagem, mas podemos, contudo, tentar ilustrá-la melhor, referindo exemplos de vieses que, segundo Kouabénan (2007, p. 301-302), intervêm frequentemente na explicação e na percepção dos acidentes e dos riscos:

$\checkmark$ Vieses motivacionais: auto-proteção, defesa da estima de si, auto-apresentação positiva, vontade de acreditar num mundo justo, negação defensiva, etc.;

$\checkmark$ Vieses cognitivos: tratamento deficiente das informações, seletividade das informações, heurística da co-variação, apreciação exagerada das aptidões pessoais e de poder/otimismo irrealista/vieses de superioridade/ilusão de invulnerabilidade, etc.;

$\checkmark$ Vieses normativos: normas de avaliação mais severas para acontecimentos graves, importância do carácter consensual do comportamento, sua moralidade e desejabilidade social, etc.

Não deixa também de ser interessante situar o padrão metodológico então definido para realizar as intervenções e as pesquisas. E para o efeito, apresentaremos uma descrição sintética de uma investigação-ação que Kouabénan nos apresenta no seu contributo ao Traité de psychologie du travail et des organisations (KOUABÉNAN, 2007, p. 323-326). Ele distingue as seguintes etapas:

- Uma primeira fase de observação, repetida duas vezes, da atividade de recolha de uma amostra de sangue, com 30 enfermeiras de 3 serviços diferentes de um mesmo hospital, tendo em 
conta a check list dos 24 gestos definidos nos protocolos prescritos que visam prevenir os riscos de contaminação.

- A administração de três questionários de modo a:

a) Avaliar o conhecimento dos riscos e dos procedimentos de segurança a respeitar por parte das enfermeiras: questionário de escolha múltipla construído a partir de uma documentação consagrada nesta área;

b) Obter dados relativos à autoavaliação do risco de contaminação (vulnerabilidade): escala com 11 itens;

c) Avaliar o grau de ansiedade face às doenças: questionário pré-existente e já validado.

- Pelos tratamentos estatísticos realizados a partir dos dados assim reunidos, foi possível associar as percentagens de respeito dos 24 gestos definidos como seguros a outras variáveis.

- Os resultados evidenciaram, em particular, diferenças significativas entre os 3 serviços envolvidos no estudo. O que levou a equipe de investigação a concluir "que o melhor preditor do comportamento de uma enfermeira é o comportamento das suas colegas de serviço" (tradução nossa). Daí que a equipe tenha formulado a hipótese da existência de um fenómeno de micro-organização que "se constrói segundo modalidades psicossociais (normalização, moldagem, pressão para a conformidade [...] e que produz um efeito de homogeneização das práticas, podendo ir até ao não respeito de precauções indicadas" (tradução nossa).

- $\quad$ Por fim, refere que "a melhoria da segurança nos serviços poderá passar, sobretudo, por uma modificação da norma do grupo e, não necessariamente, por um melhor conhecimento individual dos riscos e dos procedimentos seguros" (tradução nossa).

Eis assim descrita a matriz que fundamenta este tipo de proposta de intervenção.

\subsection{Uma abordagem da 'natureza humana' que se quer lúcida}

Estamos, obviamente, perante uma análise ancorada na tradição da Psicologia social acima referida, envolvendo a noção de representação, no âmbito de uma abordagem bem distinta daquela que apresentamos na primeira parte da nossa contribuição.

O seu próprio léxico, ao privilegiar termos como ingenuidade e vieses, revela logo tal diferença que se exprime no papel assegurado pelos peritos na sua relação com "as pessoas não especializadas", mas também na própria metodologia, quando aposta no valor de instrumentos predefinidos de modo a reunir facilmente dados suscetíveis de sustentar tratamentos estatísticos adequados, e, ainda, no contraste entre a vontade de lucidez face às representações e a ausência de questionamento dos conhecimentos utilizados. Mas, fundamentalmente, transparece a convicção de que a relação (individual e coletiva) com a atividade de trabalho exprime leis comportamentais de uma "natureza humana" do nosso tempo. Este é o postulado que justifica tanto a dita necessária perspicácia do investigador, como o recurso a técnicas de recolha de dados validados previamente noutras pesquisas.

Acrescentaremos ainda que, quando este tipo de análise se inscreve no plano da intervenção, a grelha de leitura das falhas de tal natureza humana incide somente sobre a percepção e representações dos que se encontram no "fim da linha" - isto é, no caso da pesquisa referida, as enfermeiras observadas. Porém, a argumentação de Kouabénan pretende abranger todo o tipo de comportamento humano face ao risco: daí que tenha sublinhado que a sua teoria se estende também aos comportamentos de quem concebe, define e organiza os programas e as medidas de prevenção.

Talvez a extensão da contribuição de Kouabénan no Traité de psychologie du travail et des organisations tenha sido limitada por razões de espaço, como normalmente acontece, impedindo-o de apresentar outros desenvolvimentos. De qualquer modo, facilmente se constata que, no âmbito da sua perspectiva, nos afastamos de cenários de intervenção onde são providenciados encontros entre os protagonistas de forma a privilegiar a explicitação progressiva e dialógica de experiências, a criação de espaços para o debate, a controvérsia, a confrontação e o enriquecimento mútuo dos diferentes registros do conhecimento.

$\mathrm{Na}$ verdade, os ergonomistas, que no âmbito de intervenções multidisciplinares integraram contributos de Kouabénan (COTTIN; VALLERY; DAHAK, 2016; ULLILEN-MARCILLA; GARRIGOU, 2016), não abdicaram do acervo teórico e metodológico herdado da geração de Dimitri Ochanine. Este contributo da Psicologia social serve-lhes de fato como uma das vias de interpretação dos argumentos utilizados pelos protagonistas das suas investigações, quando descrevem as suas relações com o uso dos EPI. E, uma vez repertoriados os vieses motivacionais, cognitivos ou normativos, estes são integrados numa análise mais larga, isto é multifacetada, da problemática em questão, sendo igualmente objeto de debate com os participantes.

É para nós evidente que o ecletismo adotado por estes investigadores mereceria uma análise, sobretudo em termos teóricos, que esclarecesse melhor eventuais contradições metodológicas, epistemológicas e mesmo de natureza ética.

\section{Que estatuto para a noção de representação?}

"Para que serve interpor [entre o ser humano e o mundo] uma entidade psíquica entendida como reunindo os supostos determinantes do comportamento?" (ROLLE, 1997 , p. 224, tradução nossa): esta é a posição assumida por Pierre Rolle face à noção de representação, que sempre julgou bizarra, inútil na (e para) compreensão do comportamento de cada um de nós no mundo.

O veredito não deixa de ser severo, ainda mais se considerarmos o legado dos trabalhos acima referidos. 
No entanto, temos de admitir que, mais do que o interesse da própria noção de representação, foram os vários referenciais epistemológicos a ela subjacentes que despertaram o nosso interesse por esta problemática. E, neste plano, a leitura que fizemos dos dois paradigmas em questão, fica, sem dúvida, ainda melhor instruída se atendermos à distinção, conceitualizada por Yves Schwartz, entre duas formas de saber, que se caracterizam, também, através da sua relação à dimensão axiológica das nossas vidas. Segundo ele (SCHWARTZ, 2015, p. 126-127, síntese baseada em tradução livre), temos:

a) por um lado, os saberes que tornam neutros os projetos que visam conhecer, compreender e agir sobre o que caracteriza o nosso mundo, pretendendo enriquecer um património comum por meio do grau de generalidade e de uma relativa abstração. Trata-se de saberes cuja produção e descoberta alimentam o mundo dos 'profissionais dos conceitos', isto é, o mundo académico tradicional. Tal postura de distanciamento face às solicitações do presente e de 'caça' aos vieses relacionados com as circunstâncias locais, exprime uma atividade, um esforço sustentado pela procura da verdade (ou que pretende sê-lo). Aqui, a dimensão axiológica reside no próprio esforço do investigador na procura da verdade - esforço esse que, obviamente, pode ser deturpado e tornar-se refém da história e das suas tensões;

b) e, por outro, os saberes mais concretos: aqueles que, ancorados nas 'aderências locais' e nas contradições do social acabam na penumbra dos saberes 'instituídos', mas que retrabalham as prescrições, provenientes em geral dos saberes com vocação generalizante, dos quais, supostamente, se espera uma mera aplicação. Trata-se de saberes 'investidos' na e pela experiência, suscetíveis de questionar as categorias e os conceitos ditos perenes, de desestabilizá-los por vezes, exigindo eventualmente a sua reorganização ou a sua melhoria, provocando casualmente uma ruptura paradigmática. Neste segundo polo de saberes, enraizados na atividade humana e emergindo dela, são avaliadas em cada instante as condições em que se pode tentar viver. Aqui, a dimensão axiológica reside na opção, no esforço do investigador em estar atento aos valores in situ, e de aceitar o 'desconforto intelectual' ao deixar interpelar constantemente os seus modelos interpretativos, as suas categorias de análise e os conceitos baseados nos seus critérios de cientificidade.

Se na primeira postura admitimos que a noção de representação pode mesmo adquirir o estatuto de conceito, na segunda tal noção pode nem ser necessária, dada a centralidade do debate entre diferentes registros de saberes.

\section{Referências}

BARTHE, B. La déstabilisation des horaires de travail. In: THEBAUD-MONY, A. et al. (Ed.). Les risques du travail. Paris: Découverte, 2015. p. 223- 232.

CADET, B.; KOUABENAN, D. R. Évaluer et modéliser les risques: apports et limites de différents paradigmes dans le diagnostic de sécurité. Le Travail Humain, v. 68, n. 1, p. 7-35. 2005.

CAMPOS, P. H. F. Representações sociais, risco e vulnerabilidade. Tempus - Actas de Saúde Coletiva, Brasília, v. 6, n. 3, p. 13-34, 2012. Disponível em: http://www.tempusactas. unb.br/index.php/tempus/article/view/1153. Acesso em: 22 abr. 2016.

CHAMON, E.; MORAES, P. A representação social do risco em atividades potencialmente perigosas. Temas em psicologia, v. 19, n. 1, p. 243-252, 2011.

COTTIN, I.; VALLERY, G.; DAHAK, S. Uso situado de los EPP (equipos de protección personal) frente al riesgo biológico: Ejemplo de un laboratorio seguro de contención de nivel 3. Laboreal, v. 12, n. 2, p. 56-74, 2016. Disponível em: http:// www.scielo.mec.pt/scielo.php?script=sci arttext\&pid=S1646$52372016000200005 \& \operatorname{lng}=p t \& n r m=i \&$ tlng=es. Acesso em: 25 jan. 2017.

DURKHEIM, E. Règles de la méthode sociologique (1894). Paris: Payot, 2009.

DURRIVE, L.; SCHWARTZ, Y. Glossário da Ergologia. Laboreal,v.4,n. 1,p.23-28.2008. Disponívelem: http://laboreal. up.pt/revista/artigo.php?id=48u56oTV6582234396587;63882. Acesso em: 13 set. 2016.

FAVERGE, J. M. L'analyse du travail en termes de régulation. In: FAVERGE, J. M. et al. (Org.). L'ergonomie des processus industriels. Bruxelles: Université Libre de Bruxelles, 1966. p. 33-60.

FREIRE, P. Pedagogia do oprimido. 23. ed. Rio de Janeiro: Paz e Terra, 1994.

GARRIGOU, A.; BALDI, I.; DUBUC, P. Contributos da ergotoxicologia na avaliação da eficácia real dos EPI que devem proteger do risco fitossanitário: da análise da contaminação ao processo colectivo de alerta. Laboreal, v. 4, n. 1, p. 92-103, 2008. Disponível em: http://laboreal.up.pt/revista/artigo. php?id=48u56oTV65822343965;7:73962. Acesso em 22 dez. 2017.

JODELET, D. Les représentations sociales. Paris: PUF, 1997.

JODELET, D. Representações sociais na comunidade científica brasileira. Temas em psicologia, v. 19, n. 1, p. 19-26. 2011.

KOUABÉNAN, D. R. Décision, perception du risque et sécurité. In: BERNAUD, J. L.; LEMOINE, C. (Dir.). Traité de psychologie du travail et des organisations. Paris: Dunod, 2007. p. 285-326.

LACOMBLEZ, M. De Faverge à Vergnaud: entre variabilité et invariants dans le développement de l'activité. In: MERRI, M. (Coord.). Activité humaine et conceptualisation - Hommage à Gérard Vergnaud. Toulouse: Universitaires du Mirail, 2007. p. 219-225.

MARQUIÉ, J.-C.; PAUMÈS, D.; VOLKOFF, S. (Dir.). Le travail au fil de l'âge. Toulouse: Octarès, 1995. 
MILleR, G. A.; GALANTER, E.; PRIBRAM, K. H. Plans and the Structure of Behavior. New York: Holt, Rhinehart \& Winston, 1960.

MOLINIÉ, A. F.; GAUDART, C.; PUEYO, V. (Coord.). La vie professionnelle: âge, expérience et santé à l'épreuve des conditions de travail. Toulouse: Octarès, 2012.

MOSCOVICI, S. La psychanalyse son image son public. Paris: PUF, 1961.

MOSCOVICI, S. Prefácio. Temas em psicologia, Ribeirão Preto, v. 19, n. 1, p. VII-X, jun. 2011. Disponível em: http:/ pepsic.bvsalud.org/pdf/tp/v19n1/v19n1a02.pdf. Acesso em: 18 out. 2017.

MOURA, L. et al. Risco ergonômico: representações sociais de estudante de odontologia. Revista Cuidado é Fundamental, v. 5, n. 6, p. 36-44. 2013. Disponível em: http://www.redalyc.org/ html/5057/505750944005/. Acesso em: 24 mar. 2016.

MUNIZ, H. P. et al. Ivar Oddone e sua contribuição para o campo da saúde do trabalhador no Brasil. Revista brasileira de saúde ocupacional, v. 38, n. 128, p. 280-291, 2013.

OCHANINE, D. Rôle de l'image opérative dans la saisie du contenu informationnel des signaux. Questions de psychologie, n. 4, p. 209-224, 1969.

OCHANINE, D. Papel da imagem operativa na apreensão do conteúdo informacional dos sinais. Laboreal, v. 9, n. 1, p. 95-102, 2013. Disponível em: http://laboreal.up.pt/pt/articles/ papel-da-imagem-operativa-na-apreensao-do-conteudoinformacional-dos-sinais. Acesso em: 12 out. 2017.

ODDONE, I. De la médecine à une psychologie de la santé au travail. In: TEIGER, C.; LACOMBLEZ, M. (Coord.). (Se) Former pour transformer le travail: dynamiques de constructions d'une analyse critique du travail. Québec: Presses Universitaires de Laval \& Bruxelles/European Trade Union Institut, 2013. p. 174-178.

ODDONE, I.; RE, A.; BRIANTE, G. Esperienza operaia, coscienza di classe e psicologia del lavoro. Torino: Einaudi, 1977.

OUVRIER-BONNAZ, R.; WEILL-FASSINA, A. (Coord.). L'analyse du travail d'Ombredane et Faverge, 60 ans après. Toulouse: Octarès, 2015.

POESCHL, G. Teoría de las representaciones sociales. In: DOMINGUEZ, J. F. M.; CASAL, C. H. (Dir.). Estudios de psicología social. Porto: Cuadernos de la UNED, 2013. p. 439466.

POESCHL, G.; RIBEIRO, R. Inserções sociais e tomadas de posição: efeito das pertenças sociais nas representações da globalização. In: VALENTIM, J. P. (Ed.). Representações sociais: perspectivas teóricas no estudo do pensamento quotidiano. 2017. No prelo.

QUÉINNEC, Y.; TEIGER, C.; TERSSAC, G. (Dir.). Repères pour négocier le travail posté. Toulouse: Octarès, 1985.

RE, A. Une nouvelle perspective pour la compétence ergonomique dans l'analyse du travail. In: TEIGER, C.; LACOMBLEZ, M. (Coord.). (Se) Former pour transformer le travail: dynamiques de constructions d'une analyse critique du travail. Québec: Universitaires de Laval, 2013. p. 644-647.

ROLLE, P. Pierre Naville: de la psychologie à la sociologie. L'orientation scolaire et professionnelle, v. 26, n. 2, p. 249-258. 1997.

Fractal, Rev. Psicol., v. 30 - n. 2, p. 86-93, 2018
SCHWARTZ, Y. Le paradigme ergologique ou un métier de philosophe. Toulouse: Octarès, 2000.

SCHWARTZ, Y. Actividade. Laboreal, v. 1, n. 1, p. 63-64. 2005. Disponível em: http://laboreal.up.pt/revista/artigo. php?id=48u56oTV658223469:53635622. Acesso em: 19 dez. 2017.

SCHWARTZ, Y. Concepções da formação profissional e dupla antecipação. Trabalho \& Educação, v. 22, n. 3, p. 17-33, 2013.

SCHWARTZ, Y. Production de savoirs sur l'activité: quels nœuds ente épistémologie et éthique ? Ergologia, v. 14, p. 117$129,2015$.

TEIGER, C. Représentation du travail et travail de la représentation. In: WEILL-FASSINA, A.; RABARDEL, P.; DUBOIS, D. (Coord.). Représentations pour l'action. Toulouse: Octarès, 1993. p. 311-344.

TEIGER, C. et al. Dynamique de la compréhension et de la transformation du travail. Éléments pour une histoire de la coopération syndicats-recherche en ergonomie et psychologie $\mathrm{du}$ travail en France. Nouvelle revue de psychosociologie, v. 18, p. 125-210, 2014. Cross ${ }^{\text {Ref. }}$

ULLILEN-MARCILLA, C.; GARRIGOU, C. La influencia de la percepción del riesgo en la utilización de los equipos de protección individual contra los pesticidas. Laboreal, v. 12, n. 1, p. 12-22, 2016. Cross ${ }^{\text {Ref }}$

VASCONCELOS, R.; LACOMBLEZ, M. Redescubramonos na sua experiência: o desafio que nos lança Ivar Oddone. Laboreal, v. 1, n. 1, p. 38-51, 2005. Disponível em: http:// laboreal.up.pt/files/articles/2005_12/pt/7_Ricardo\&Marianne PT.pdf. Acesso em: 18 dez. $201 \overline{7}$.

WEILL-FASSINA, A. A imagem operativa de Dimitri Ochanine em contexto: uma introdução aos textos de D. Ochanine e C. Teiger. Laboreal, v. 9, n. 1, p. 84-91, 2013. Disponível em: http://laboreal.up.pt/pt/articles/a-imagem-operativa-de-dimitriochanine-em-contexto--uma-introducao-aos-textos-de-dochanine-e-c-teiger/. Acesso em: 15 abr. 2017.

WEILL-FASSINA, A.; RABARDEL, P.; DUBOIS, D. (Coord.). Représentations pour l'action. Toulouse: Octarès, 1993.

WORMS, F. La philosophie en France au XXe siècle: moments. Paris: Gallimard, 2009.

Recebido em: 11 de setembro de 2017 Aceito em: 28 de junho de 2018 